\title{
In memory of Professor José António Tenreiro Machado (1957-2021)
}

\author{
Carla M. A. Pinto • António M. Lopes • \\ Alexandra M. S. F. Galhano
}

Received: 15 December 2021 / Accepted: 17 December 2021 / Published online: 5 January 2022

(C) The Author(s), under exclusive licence to Springer Nature B.V. 2022

\section{Short biography}

Professor José António Tenreiro Machado (Fig. 1) was born on October 6, 1957, in Pinhel, Portugal, and passed away, unexpectedly on October 6, 2021. At the age of two, after his mother separated from his father, he and his mother went to live with his maternal grandparents in Porto. His grandparents were his family pillars. At the age of fifteen, his grandmother died of cancer and, two years later, his grandfather got remarried. In high school, he became an excellent student and started giving private lessons to other high school students, while continuing his studies. As a university student, he carried on tutoring his university peers. With this income, he paid his studies and also helped his mother

\section{M. A. Pinto $(\bowtie)$}

Department of Mathematics, Polytechnic of Porto, Institute of Engineering, Rua Dr. António Bernardino de Almeida, 431, 431 4249-015 Porto, Portugal

e-mail: cap@isep.ipp.pt

Pinto Carla

Centre for Mathematics, School of Engineering, Polytechnic of Porto, University of Porto, Porto, Portugal

A. M. Lopes

LAETA/INEGI, Faculty of Engineering, University of

Porto, Rua Dr. Roberto Frias, 4200-465 Porto, Portugal e-mail: aml@fe.up.pt

A. M. S. F. Galhano

Faculdade de Ciências Naturais, Engenharias e

Tecnologias, Universidade Lusófona do Porto, Rua

Augusto Rosa 24, 4000-098 Porto, Portugal

e-mail: alexandra.galhano@ulp.pt financially. During the same period, he was a chess player and won many trophies. He finished his Electrical Engineering degree with the highest classification and received the Eng ${ }^{\circ}$ Cristiano P. Spratley award from the University of Porto.

Professor Tenreiro Machado academic career started in 1980 as an assistant professor at the Faculty of Engineering of the University of Porto (FEUP). Also in the beginning of his professional activity, he worked in industry, more specifically in fluid-power hydraulics and electronics in 1983. From 1985 to 1988, Professor Tenreiro Machado took a leave of absence to establish a new engineering college at the Polytechnic Institute of Viseu (Viseu, Portugal). He defended, in 1989, his $\mathrm{PhD}$ thesis entitled "Structural Resource Management in the Control of Robot Manipulators" and, in 1995, the "Habilitation," where he presented the overview lesson "Computational Problems in Robot Control," at the University of Porto.

His work at the Department of Electrical and Computer Engineering of FEUP ended in 1998, carrying on his academic career at the Department of Electrical Engineering, in the Institute of Engineering of the Polytechnic Institute of Porto (ISEP) as a Coordinator Professor. He was assigned as Principal Coordinator Professor at ISEP in 2016. In that capacity, he became the dean of both the Institute of Engineering and the Polytechnic Institute of Porto.

Throughout his academic activity, Professor Tenreiro Machado was director of several $1^{\text {st }}$ and $2^{\text {nd }}$ degree 


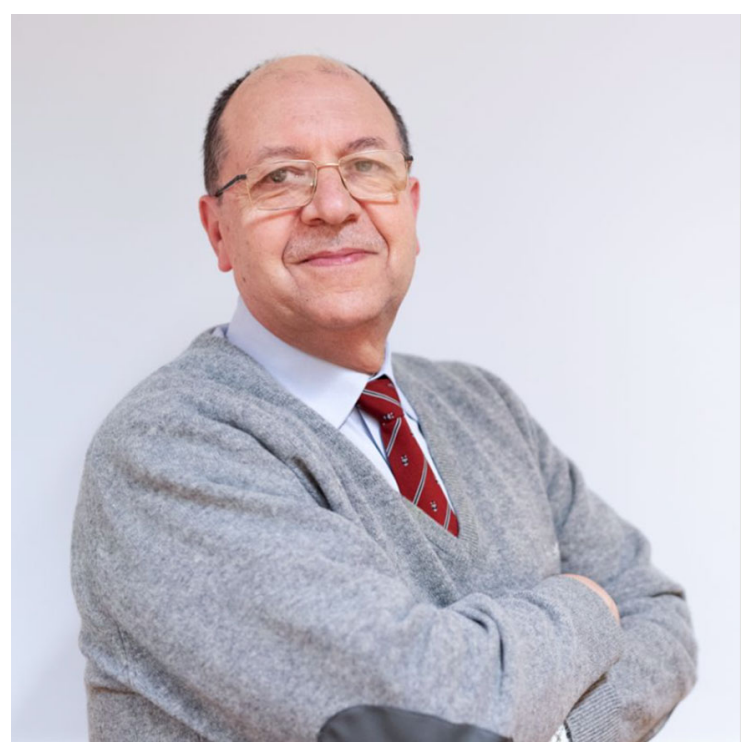

Fig. 1 Professor Tenreiro Machado in 2020 at the Department of Electrical Engineering, Institute of Engineering, Polytechnic Institute of Porto

(licenciatura and master's degrees) university courses on Automation and Control, Management, and Electrical and Computer Engineering. He also performed tasks such as Head of Department of Electrical Engineering, President of the Scientific Committee of the Institute of Engineering, Member of the General Council of the Polytechnic Institute of Porto and Scientific Coordinator of Interdisciplinary Studies Research Center, also at the Polytechnic Institute of Porto. He was supervisor of 16 concluded and 3 ongoing $\mathrm{PhD}$ theses and was a member of PhD juries in Portugal, Brazil, Spain, France, Belgium, Finland, Poland, and Czech Republic.

From the very beginning, Professor Tenreiro Machado was a dedicated and helpful professor. $\mathrm{He}$ was a wonderful communicator, always seasoning his classes with a touch of humor that hooked his students and drew them into the subjects he taught. $\mathrm{He}$ taught students of all levels and participated in courses in other Portuguese universities, as well as abroad. He was a supervisor and lecturer of the Doctoral School of Applied Informatics in Óbuda University, Budapest, Hungary, since 2013. He was a visiting professor at the Institute of Applied Computer Science, Lodz University of Technology, Poland since 2014. In 2016, he received the Appointment Certificate "Guest Outstanding Professor at Sichuan University of Science and
Engineering," by the university President Tuo Xiangguo, Zigong, Sichuan, China.

His research interests spanned a very wide range of topics including electrical machine control, electronics and fluid-power hydraulics, robotics (position and force control, legged locomotion, modeling, computational architectures, biomechanics and education), nonlinear dynamics, complex systems, fractional-order systems, time series analysis, genetic algorithms, evolutionary computing, intelligent transportation systems, vibration control, analysis of mechanical systems with friction and backlash, electromagnetism, bioinformatics, genomics, computational cybernetics, financial analysis, economy dynamics, music, paintings and entropy.

He authored over 1160 publications, including 11 books, 575 journal papers, 118 book chapters, 382 presentations, and 60 plenary lectures at national and international meetings and conferences, and 74 courses in national and international universities. He was editor of 22 books, advisory editor of 3 book series and editor in chief of 1 book series. He was also scientific director of journal "Robotics and Automation" (in Portuguese), guest-editor of 55 special issues in journals, member of the editorial board, associate editor in several scientific journals and editor-in-chief of 3 scientific journals. He is a Highly Cited Researcher in the category Cross-Field of Clarivate Analytics. His scientific achievements are wide, deep and overarching. His impact on the literature is truly remarkable.

\section{Main research themes}

In the following, we will single out Professor Tenreiro's scientific legacy as directly, or more subtly, embedded in different topics, gathered within three main macro themes. Although the topics he addressed cannot be considered as totally independent, it is worth highlighting some of his contributions on Control \& Robotics, Complex Systems and Fractional Calculus. We will point out both methodological and application perspectives.

\section{- Control and Robotics}

As mentioned, Professor Machado's background was from Electrical Engineering. He started his scientific activity in the area of control and robotics but, with his unbounded passion for science and unlimited energy, he was always eager to embark on new challenges, and soon he started embracing 
other research subjects. Indeed, he was interested in dozens of topics, contributing with his innovative ideas, which for sure will inspire many others in the years to come.

Professor Tenreiro Machado gave important contributions to the area of variable structure controllers (VSC) of mechanical manipulators. His first publications on the topic suggested the use of second order reference models $[1,2]$ to improve the reaching and sliding phases, while mitigating chattering. Later, he continued pursuing these control goals by embedding the concepts of fractional calculus (FC) with VSCs $[3,4]$. Nevertheless, the contributions of Professor Tenreiro Machado to the area of control went beyond those already mentioned and included the development of other control techniques, such as computed torque [5] and fractional PID controllers [6]. In particular, the hybrid force-torque control interested Professor Tenreiro Machado for long, with emphasis in the 1990s. Indeed, he proposed several ideas to improve the interaction performance between manipulator and environment [7], between cooperating manipulators [8], and between legged robots and terrain [9]. Other ideas well-explored by Professor Tenreiro Machado were adopted in robot manipulators trajectory planning, and kinematics and dynamics analysis and optimization. We can refer to the use of statistical approaches to model robot kinematics $[10,11]$, evolutionary computing for robot optimization [12], nonlinear analysis for identifying rich dynamical phenomena on robot motion [13] and techniques for exploring manipulator redundancy [14]. Legged robots, namely bipeds and hexapods, were studied by Professor Tenreiro Machado. His contributions could help others pursuing advancements in the state of the art in gait modeling, kinematic optimization, performance analysis and control, just to cite a few $[15,16]$. Still touching the area of mobile robots, he worked on intelligent transportation systems modeling and control $[17,18]$. In the last few years, Professor Tenreiro Machado contributed with relevant findings in control, namely robust and optimal techniques in the framework of FC [19-23]. Recently, Professor Tenreiro Machado proposed to address the performance of a controlled system as a multidimensional problem and to use dimensionality reduction, clustering and computer visualization tools to assess dynamical behavior [24,25]. In this regard, his last paper was "Fractional-Order Sensing and Control: Embedding the Nonlinear Dynamics of Robot Manipulators into the Multidimensional Scaling Method," which was concluded a couple of days before he passed away, and published on November 20, 2021 [26].

\section{- Complex Systems (CS)}

Professor Tenreiro Machado applied several computational techniques to a wide variety of topics, from mathematics and physics, to economic and financial analysis, to earthquakes, forest fires, music, paintings, to name a few. Among his scientific production, we can find works of extreme beauty [27]. In here, he proposes a computational model, which is an abstraction of the natural world, to study a discrete dynamical system of interacting particles, evolving through this interaction. The patterns that unfold are analyzed by means of fractal dimension and entropy measures. Beautiful geometric objects of fractal nature unfold as several initial conditions are simulated.

Professor Tenreiro Machado investigated entropy as a tool to characterize complex systems. As one major contribution, he proposed new entropic formulations, namely the so-called Machado's entropy [28] and other formulations in the framework of FC [29,30].

In [31], multidimensional scaling (MDS) analysis was successfully applied to data from noninvasive lung tests. The purpose was to obtain a geometrical mapping to distinguish (dis)similarities between patients in same and distinct patient groups. MDS analysis was also performed to evaluate fractional-order systems [32] and stock markets [33]. Another area of interest to MDS visualization was earthquake phenomena [34]. MDS maps proved to be intuitive and useful visual representations of complex relationships of seismic events. MDS was also a powerful tool to study the quantitative and qualitative behavior of 22 viral infectious diseases [35]. In another completely different scenario, MDS was the preferred tool to study the performance of soccer teams in national leagues [36].

Added to MDS, other tools were commonly recurrent in his papers, namely entropy analysis, fractal dimension, entropy, state space portrait, power laws. A review of power law (PL) distri- 
butions can be found here [37]. In [38], global terrorism patterns, from 1970 till 2014, were the main object of investigation.

The Special Issue in [39] is devoted to novel theoretical and practical works, and computational algorithms, applied to complex problems, which require heavy computational resources. Examples go from a novel telemedicine technology to remotely control Parkinson's disease, detection of weak signals in ocean ambient noise, statistical and dynamical techniques to derive better candidates to empirical laws to model nature, network-based quantitative methods to help investors identifying the actual strategy of open-ended funds, multilevel formation model for complex software systems, among others.

In 2020, Professor Tenreiro Machado et al analyzed the dynamics of SARS-CoV-2 propagation, using statistical comparison and visualization of country-based real data [40]. The studied period was December 31, 2019, up to April 12, 2020, and consisted of two different perspectives. The time series of the number of infected people in 79 countries was modeled by heuristic models, fitting the real-world data. Furthermore, hierarchical clustering and multidimensional scaling were applied to compare different countries. Main outcomes suggest similarities and differences between countries and add to the understanding of the COVID-19 spread.

Also in 2020, Professor Tenreiro Machado et al [41] performed a computational analysis of SARSCoV-2 and other viruses, by means of the Kolmogorov's complexity and Shannon's information theories. The later shaded new relations between distinct RNA viruses.

As a final note, one can securely say that Professor Tenreiro Machado was a man of science, proficient researcher in a wide range of fields, and his legacy will endure to future researchers.

\section{- Fractional Calculus (FC)}

Professor Tenreiro Machado most prolific scientific production is associated with FC. His first FC paper [42] was published in 1997 and analyzed and designed fractional-order digital control systems. Since 1997, Professor Tenreiro worked and wrote several papers on the topic, of which 51 as a single author. His most cited work "Advances in Fractional Calculus" [43] is a book containing 37 papers on the applications of FC, which expresses FC as a viable mathematical tool to surpass integer-order models' imperfections. This book is followed, in 2011 , by another highly cited work "Recent History of Fractional Calculus" [44], in which it is done a survey of the major documents and events in the area of FC, taking place since 1974, up to 2010. In 2019, he published a multivolume book series entitled Handbook of Fractional Calculus with Applications with a total of 8 volumes [45]. The first volume is devoted to the cover of the mathematical theory of fractional calculus, including fractional-order operators, integral transforms and equations, special functions, calculus of variations, and probabilistic and other aspects. This is followed in the second volume by the mathematical theory of fractional calculus, including ordinary and partial differential equations of fractional order, inverse problems, and evolution equations. In volume 3 are provided numerical aspects of fractional calculus, including time and space fractional derivatives, finite differences and finite elements, and spectral, meshless, and particle methods. Fractional calculus in physics, including classical and continuum mechanics, is presented in the fourth volume. Applications of FC in physics are done in volume 5. They include electrodynamics, statistical physics, physical kinetics, and quantum theory. Volume 5 is devoted to applications of FC in control theory, in which are presented fractional-order controllers, design methods and toolboxes, and control in engineering applications. The last two volumes present applications of FC in engineering, life and social sciences, including biology and medicine, mechanics of complex media, economy, electrical devices, signal and image analysis, and chaos.

As a single author, his most recent paper is "The bouncing ball and the Grünwald-Letnikov definition of fractional derivative" [46], from 2021, in which is proposed a conceptual experiment of a fractional-order model of a bouncing ball. The Grünwald-Letnikov (GL) formulation is applied for the derivative of fractional order. The impacts of the ball with the surface are modeled by means of a restitution coefficient related to the coefficients of the GL fractional derivative. In this sense, Prof Tenreiro provided a means of introducing, in a motivational way, a physical perspective of FC to students and with straightforward visualization. More- 
over, this adds to the discussion of application of FC models in mechanics.

Recently, in 2021, Professor Tenreiro Machado, in a joint paper with Kay Diethelm, V. Kiryakova, Y. Luchko, and V. Tarasov, entitled "Trends, Directions for Further Research, Some Open Problems of Fractional Calculus," assessed the state of development of FC and provides some hints to future evolution, pointing the challenges ahead in advanced research works. Are covered several topics in mathematics, numerical algorithms, and physics [47].

Prof Tenreiro Machado's legacy in FC is vast, covering from theoretical to practical aspects, and is a source of inspiration to works from researchers in the FC field. The latest developments and trends in applications of FC in biomedicine and biology can be found in [48]. There, non-integer differ-integral solutions and non-integer parametric models are used to model the properties of respiratory lung tissue, drug diffusion, action potential, and spiking patterns in neurons, bio-systems. The paper is a valuable reading material to an engineer with multidisciplinary applications.

\section{Testimonials from some colleagues}

In this section, we add testimonials of several renowned international researchers, who have collaborated with Professor Tenreiro Machado, throughout his academic life.

- Professor D. Baleanu, Institute of Space Sciences, Romania, and Cankaya University, Turkey.

Professor J. A. Tenreiro Machado was a great researcher in the areas of fractional calculus and complexity with important contributions in spreading these powerful concepts to the entire scientific community. He always told us to work on the hot complicated new topics having a huge impact on science and engineering.

Tenreiro was the first person who introduced me to the fractional calculus community, and he suggested attending the FDA meeting which took place in Bordeaux, France, in 2004. After this event, until he died on October 6, 2021, we were the co-authors of several top-level books published by Springer, as well as of various research papers published in prestigious ISI journals. Also, under Tenreiro's supervision, I and Antonio Mendes Lopes have edited vol- umes 7 and 8 of the prestigious Handbook of Fractional Calculus with Applications published by De Gruyter in 2019. Besides, I and Tenreiro have organized, together with other colleagues and friends, several successful international conferences like the FDA meeting at Cankaya University, Turkey in 2008, or ICAME'20 meeting at Balikesir University, Turkey in 2020.

During several international scientific events, I and my wife Cristina had many unique opportunities to speak with Tenreiro on various topics from science, engineering, and culture. He always was smiling and delivered us positive energy. Besides, Tenreiro with his original sense of humor always gave us the right advice for any type of complicated problem that we have shared with him.

With his kindness and warm character, he helped several young researchers from over the world to become familiar with fractional calculus and complexity. His great personality had an important influence on many young researchers and academicians. With his huge capacity for doing well in very different types of activity, he always was able to guide optimally different non-homogeneous groups of researchers. Tenreiro always spoke with admiration and deep respect about his lovely family and his beautiful city Porto. We will remember Tenreiro as a top-level researcher, a man with a big heart and a true friend. God bless you Tenreiro!

- Professor R. El-Khazali, Khalifa University, Abu, Dhabi, UAE.

If words could depict the true depth of a person's soul, this obituary may never end in attempting to remotely reach the level of achievements in Professor José António Tenreiro Machado in his work and personal life. Despite the success he's made, he kept true to himself, an honest man of good virtue, kindness and a friendship of a lifetime is what one gained from such a wonderful person. Machado could strike a camaraderie with anyone, making one feel understood and connected to in more ways than one. He was beloved by many, acknowledged worldwide and seen as a man of not only good faith, but a good heart, whose loss will surely be felt for as long as we may live. I had the pleasure to befriend Machado in 2006, repeatedly finding ourselves meeting all over the world in Italy, Portugal, Spain, Russia, and more. He was always a man full of wisdom, the type of person who was 
part of a solution and never a problem. His brilliant mind inspired many, myself included, and always had more to give and say every time you met him. An ingenious spirit full of life, exceptional in all that he did, with a smile on his face and a pat on the back, one always found himself in ease with Tenreiro Machado. May his soul rest in peace, till we meet again.

- Professor R. Garrappa, Università degli Studi di Bari Aldo Moro, Italy.

When, with sadness, I try to collect my thoughts related to José António Tenreiro Machado, I can think of three adjectives that best describe the memory I have of him: friendly, enthusiastic, and untiring. It was really hard not to become friends with Tenreiro. Each conference was a good opportunity for him to offer everyone (whether they were young students or distinguished colleagues) his friendship, his desire to socialize. He was always in the middle of some pleasant conversation, with some of his several stories and anecdotes. Tenreiro was a curious man, maybe the most important gift for a scientist, and he loved to share with others any fruit of his curiosity. His enthusiasm seemed to be boundless. He always gave the impression that his job was not a work for him, but a passion to which he devoted himself with great excitement. And he was always eager to contaminate others with his enthusiasm. He was never tired of embarking on some new activity: a new editorial project, the organization of a round table or a conference, working on a new topic. He appeared to possess an inexhaustible reservoir of energy: if there was something to be done, it had to be done! We all remember his ability to borrow the title of a song, a famous sentence, or the title of a painting to name, in a captivating but meaningful way, a conference, a round table, or a paper. Maybe, one of his most successful titles was "Fractional calculus's adventures in Wonderland." Today I can't stop thinking of Tenreiro as a kind of Alice in Wonderland, driven by his curiosity and enthusiasm and, mainly, by his tireless desire to share his passion and his knowledge with all of us. We will always miss Tenreiro, not only for his scientific achievements, but in a special way for his amazing personality.

- Professor K. Hedrih, the Mathematical Institute of the Serbian Academy of Sciences and Arts, Serbia. When Professor Tenreiro Machado passed away, I felt deep sadness, that such a strong person, with his great scientific and organizational abilities, left us in the scientific "arena" of gatherings, journals and conference publications. Just as Professor Tenreiro Machado was dedicated to his family, his wife Alexandra, his two sons, so he was present in the international scientific community with a lot of dedication. He has organized a large number of Workshops from fractional calculus and applications, as well as a large number of mini-symposia at Nonlinear Dynamics Conferences organized by EuroMech (European Society of Mechanics), as well as other scientific events around the world.

My scientific acquaintance with Professor Machado dates back to 2004, when I participated in the IFAC workshop on Fractional Differentiation and its Applications FDA 04, ENSEIRB, Bordeaux, France, July 19-21, 2004, following his invitation, based on one of my papers on longitudinal oscillations of rods of variable cross section, made of fractional type material. Professor Machado and I published a joint coauthored article in 2015, entitled: Discrete fractional order system vibrations, International Journal Non-Linear Mechanics. Professor Machado paid special attention to young researchers and their connections at scientific gatherings, especially in the field of Fractional Differentiation and its Applications.

It was really a great honor to meet such a person, man and scientist, with his sincere benevolence, great active energy and dedication, not only to his family, but also to the entire international scientific community.

- Professor V. Kiryakova, Bulgarian Academy of Sciences, Institute of Mathematics and Informatics, Bulgaria.

We lost the never tired and ever fighting Don Quixote of the Fractional Calculus (FC), its great promoter and so active researcher. Till his last breath he was initiating papers, books, events, and special issues, served to many journals, chaired a conference session, full of energy and life!

Only few of the words said by our colleagues immediately after the sad news, are: "great men," "devastating sad news," "enthusiastic professional," "artist of FC," "one of pioneers of FC who helped to animate and gather our community."

Despite his numerous roles as author, editor, organizer of conferences and various events, he 
served also as Associate Editor of another journal, "Fractional Calculus and Applications." We express the deep sorrow feelings also of the members this Editorial Board and of the Steering and Program Committees of the International Conferences on Fractional Differentiation and Applications (ICFDA) and their participants.

- Professor Y. Luchko, Beuth Hochschule für Technik Berlin, Faculty of Mathematics, Physics, Chemistry, Germany.

Even if Prof. Machado was an engineer and not a mathematician, his mathematical abilities, mathematical horizon, and the broadness of his mathematical interests were impressive and exceptional. In addition to his profound contributions to fractional calculus, he was interested in complex systems, nonlinear dynamics, computer simulations, and dozens of other mathematical theories and topics. As an example, I mention our recent joint paper devoted to multidimensional scaling and visualization of patterns in distribution of non-trivial zeros of the Riemann zeta-function. Prof. Machado who tried to make a progress in resolving the celebrated Riemann hypothesis regarding the distribution of the zeta-function suggested the idea for the paper. The results that we derived and presented in this joint paper were a surprise even for professional mathematicians specialized in this field. This is just one example out of many dozens of serious and often very surprising contributions of Prof. Machado to mathematics. His innovative mathematical ideas and contributions will for sure serve as an inspiration for mathematicians for a long time.

- Professor A. Luo, Southern Illinois University Edwardsville, USA.

I knew Professor J. A. Tenreiro Machado since 2003 as a pioneer working on fractional calculus. He was recommended by Professor George M. Zaslavsky to strengthen the editorial board of Communications in Nonlinear Science and Numerical Simulation in fractional calculus and nonlinear dynamics. Since then, Tenreiro and I worked together in the field of nonlinear dynamics. He is one of the best friends and a very productive scientific colleague. Tenreiro's contributions are on the power laws of chaos based on fractional calculus and control design based on fractional dynamical systems. Tenreiro initiated large data analysis and genomics classification from information entropy.
Tenreiro with me developed the L\& H scientific publishing to help scientific publishing and brought a new fresh air for scientific publishing. Herein, Tenreiro's contributions on science and our society will last forever. Dear friend, Tenreiro, this world will remember your name and your contributions. God bless you, my friend!

- Professor F. Mainardi,, Retired Professor at the University of Bologna, Italy.

I am sure that all the community of fractional calculus has recognized the enthusiasm and the generosity of the late Prof Machado. He has paid with His life these characteristics dying prematurely at 64 years of age (of heart attack), before his retirement. It is a great loss for our community.

I fully support any initiative for remembering him adequately. I have personal and strong memories of our acquaintance in several congresses (shared also with my wife) starting from FDA06 that he organized in Porto in 2006 and continued up to nowadays.

- Professor M. Ortigueira, UNINOVA-Instituto de Desenvolvimento de Novas Tecnologias, Portugal. I want to express my gratitude and tribute to a great man and scientist. He was a very friendly and helpful person, with an unusual work capacity that allowed him to publish interesting articles on a wide range of topics. I miss our weekly conversations already.

- Professor A. Oustaloup and P. Melchior, Institut Polytechnique de Bordeaux, France.

With his kindness, his warm character, and his sophisticated sense of humor, José had a reassuring presence which helped the flow of exchanges at all levels. In our exchanges, I could always benefit from his qualities. Not to mention, he made the effort to speak French providing me the comfort of using my native language. He was one of the first to unity our community and make it known. Indefatigable traveler, he reinforced the bond among researchers and had a good measure of the potential of the international community. Through his extensive scientific culture, he helped and advised several young researchers and was at the origin of numerous international collaborations. With his generosity, openness and federating character, he was like mortar to unify the community. He has always privileged collective organizations favoring the diffusion of work from several colleagues. In 
fact, he was a true ambassador for our community and we shall not forget.

- Professor J. Tar, Óbudai Egyetem, Institute of Applied Mathematics, Hungary.

Since we met in the nineties of the past century, professor Tenreiro Machado became one of my closest friends. I always amused his comprehensive mathematical knowledge and deep understanding in control issues, in the application of fractional calculus in control and data analysis. We had certain common projects, too. However, in his private life he also did huge efforts for propagating culture and science, for educating the younger generation. Together with other scientists, I often enjoyed his and his family's kind hospitality in his wonderful home at Oporto, where scientific subjects were discussed, too. With his death I have lost a "fixed point" in the world. Let him rest in peace!

- Professor V.E. Tarasov, Lomonosov Moscow State University, Russia.

Professor Tenreiro Machado was a very versatile scientist. He studied new fields of science with interest and began to actively work in them and publish articles in leading scientific journals. I admired his activity and the ability to organize other scientists. One of his last scientific works, in collaboration with other scientists, was a survey on fractional calculus, and its applications, in which he was the main organizer and inspirer. The last email message he sent me on his last day was about this review article. I hope this work will be published in the near future in the journal Nonlinear Dynamics Under his leadership and on his initiative, an eight-volume Handbook of Fractional Calculus with Applications was written and published in 2019. This monumental work would not have appeared without Tenreiro Machado, and I think this work of his will play a huge role in this science for many decades to come. Unfortunately, personally, or rather, not online, I met with Tenreiro Machado only once, namely at a conference in Serbia in 2016. I noticed his quick gait on excursions and his ability to quickly find an approach to different people. Tenreiro Machado left us very quickly, but he will be with us in our hearts, in our memory, in his in sons and scientific works.

- Professor W. Lacarbonara, Sapienza University of Rome, Italy.

I met Prof. Machado for the first time in 2017 when I was appointed Editor-in-Chief of Nonlinear Dynamics, a journal for which Tenreiro has worked tirelessly for several years as Associate Editor under the editorship of Prof. Ali H. Nayfeh. During our first meeting, I was immediately impressed by his deep knowledge and his unbounded enthusiasm for the multiple editorial and scientific activities he was involved with. However, it was only later that I fully understood the magnitude of his contributions and exceptional service to the community. Whenever I asked for his help in handling papers, launching special issues, working on review papers, or serving in panel discussions (e.g., the first episodes of Nodycast directed by Prof. C. Nataraj, https://nodycast.org) or organizing symposia and keynotes (NODYCON 2021, https://nodycon.org/ 2021), he was always ready to jump in. Over time our interactions grew in frequency and intensity. During the recent pandemic, he accepted to launch an extremely successful special issue on COVID19 [49] and later a second special issue on the new waves of COVID-19 [50]. During the same time, we came to the conclusion that we should join efforts in describing the unique multiscale dynamics of the disease spreading in Italy, the first Western country to be under an unprecedented pandemic pressure. We combined different tools and methods to identify the various temporal and spatial scales of the pandemic spreading [51]. I still remember vividly that co-authorship experience as a true privilege because he had that special spark that only great scientists have, namely an unbounded love for research which motivated him to take on new challenges without counting the extra efforts or time required to go deeper into the related investigations. Later I invited him to co-author a paper on the first thirty years of Nonlinear Dynamics, and again he enthusiastically accepted my invitation. We used cluster and multidimensional analysis to cross-analyze and uncover the richness of research published in Nonlinear Dynamics since its launch in 1990 (https://www.springer.com/journal/11071/ updates/18336212). This paper is not yet published, and it is my firm resolution to complete its writing and publication in memory of Tenreiro. We also discussed several other exciting ideas such as the hidden dynamics of artistic paintings going back to the Renaissance magnificent tradition, or the unfolding of the dynamic patterns underlined by the Euro2020 
soccer tournament. Tenreiro was a force of nature, an original thinker, an impressive achiever, to the point that I can hardly believe that he could stop his continuous flow of ideas and multiple parallel tasks. Nonlinear Dynamics will truly miss a gigantic colleague like Tenreiro with his wisdom, hard work attitude, passion for research and integrity.

We conclude this review of the scientific contributions of Professor J. A. Tenreiro Machado, dedicated to his memory, by thanking all of the renowned senior colleagues, who have shared meaningful words of appreciation and scientific recognition toward Professor Tenreiro Machado.

We also wish to thank the Editor-in-Chief of Nonlinear Dynamics, Professor Walter Lacarbonara, for suggesting this initiative to honor an internationally recognized scholar and scientist, who was also a family man.

\section{References}

1. Machado, J.A.T., de Carvalho, J.L.M.: A new variable structure controller for robot manipulators. In Third IEEE International Symposium on Intelligent Control. Arlington, Virginia, USA (1988)

2. Machado, J.A.T.: Variable structure control of manipulators with joints having flexibility and backlash. Syst. Anal. Model. Simul. 23(1-2), 93-101 (1996)

3. Machado, J. A. T., Azenha, A.: Fractional-order hybrid control of robot manipulators, in IEEE International Conference on Systems, Man and Cybernetics, San Diego, California, USA, 1998

4. Machado, J.T.: The effect of fractional order in variable structure control. Comput. Math. Appl. 64(10), 3340-3350 (2012)

5. Machado, J.T., de Carvalho, J.M., Galhano, A.M.: Analysis of robot dynamics and compensation using classical and computed torque techniques. IEEE Trans. Educ. 36(4), 372379 (1993)

6. Machado, J.T.: Optimal tuning of fractional controllers using genetic algorithms. Nonlinear Dyn. 62(1), 447-452 (2010)

7. Ferreira, N., Tenreiro Machado, J.: Fractional-order hybrid control of robots manipulators, in the 11th International Conference on Advanced Robotics, 2003, pp. 1-8

8. Ferreira, N.F., Machado, J.T., Tar, J.K.: Two cooperating manipulators with fractional controllers. Int. J. Adv. Rob. Syst. 6(4), 31 (2009)

9. Silva, M.F., Machado, J.T., Lopes, A.: Fractional order control of a hexapod robot. Nonlinear Dyn. 38(1), 417-433 (2004)

10. Tenreiro Machado, J., Carvalho, J.: A statistical approach to the analysis and design of robot manipulators, in IEEE International Workshop on intelligent robots and systems, 1988, pp. 1-8
11. Machado, J.T., Galhano, A.: A statistical perspective to the fourier analysis of mechanical manipulators. Syst. Anal. Model. Simul. 33(4), 373-384 (1998)

12. Pires, E. J. S., de Moura Oliveira, P. B., Machado, J. A. T.: Multi-objective genetic manipulator trajectory planner. In Workshops on Applications of Evolutionary Computation. Springer, 2004, pp. 219-229

13. Duarte, F.B., Machado, J.T.: Chaotic phenomena and fractional-order dynamics in the trajectory control of redundant manipulators. Nonlinear Dyn. 29(1), 315-342 (2002)

14. Machado, J.T., Lopes, A.M.: A fractional perspective on the trajectory control of redundant and hyper-redundant robot manipulators. Appl. Math. Model. 46, 716-726 (2017)

15. Silva, M.F., Machado, J.T., Lopes, A.M.: Modelling and simulation of artificial locomotion systems. Robotica 23(5), 595-606 (2005)

16. Silva, M.F., Machado, J.T., Barbosa, R.S.: Complex-order dynamics in hexapod locomotion. Signal Process. 86(10), 2785-2793 (2006)

17. L. Figueiredo, I. Jesus, J. T. Machado, J. R. Ferreira, and J. M. de Carvalho, Research issues in intelligent transportation systems. In European Control Conference (ECC). IEEE 2001, 301-306 (2001)

18. Figueiredo, L., Machado, J., Tar, J.K.: Modelling and control of freeway traffic, Intelligent systems at the Service of. Mankind 2, 3-14 (2004)

19. Alaviyan Shahri, E. S., Alfi, A., Tenreiro Machado, J.: Stability analysis of a class of nonlinear fractional-order systems under control input saturation. International Journal of Robust and Nonlinear Control, vol. 28, no. 7, pp. 2887-2905, (2018)

20. Sweilam, N., Al-Mekhlafi, S., Albalawi, A., Machado, J.T.: Optimal control of variable-order fractional model for delay cancer treatments. Appl. Math. Model. 89, 1557-1574 (2021)

21. Chen, L., Li, T., Wu, R., Lopes, A.M., Machado, J.T., Wu, K.: Output-feedback-guaranteed cost control of fractional-order uncertain linear delayed systems. Comput. Appl. Math. 39(3), 1-18 (2020)

22. Aghayan, Z.S., Alfi, A., Machado, J.T.: Robust stability of uncertain fractional order systems of neutral type with distributed delays and control input saturation. ISA Trans. 111, 144-155 (2021)

23. Dabiri, A., Poursina, M., Machado, J.T.: Dynamics and optimal control of multibody systems using fractional generalized divide-and-conquer algorithm. Nonlinear Dyn. 102(3), 1611-1626 (2020)

24. Machado, J.: Visualizing non-linear control system performance by means of multidimensional scaling, Journal of Computational and Nonlinear Dynamics, vol. 8, no. 4, (2013)

25. Lopes, A.M., Machado, J.T.: Multidimensional scaling analysis of generalized mean discrete-time fractional order controllers. Commun. Nonlinear Sci. Numer. Simul. 95, 105657 (2021)

26. Lopes, A. M., Machado, J.: Fractional-order sensing and control: Embedding the nonlinear dynamics of robot manipulators into the multidimensional scaling method. Sensors, (2021)

27. Machado, J.A.T.: Complex evolution of a multi-particle system. Appl. Math. Model. 37(22), 9203-9214 (2013) 
28. Machado, J.T.: Fractional order generalized information. Entropy 16(4), 2350-2361 (2014)

29. Ferreira, R. A., Tenreiro Machado, J.: An entropy formulation based on the generalized liouville fractional derivative, Entropy, vol. 21, no. 7, p. 638 (2019)

30. Machado, J.T., Lopes, A.M.: Fractional Rényi entropy. Eur. Phys. J. Plus 134(5), 1-10 (2019)

31. Ionescu, C.M., Machado, J.T., De Keyser, R.: Is multidimensional scaling suitable for mapping the input respiratory impedance in subjects and patients? Comput. Methods Programs Biomed. 104(3), e189-e200 (2011)

32. Machado, J.T.: Multidimensional scaling analysis of fractional systems. Comput. Math. Appl. 64(10), 2966-2972 (2012)

33. Machado, J., Duarte, F.B., Duarte, G.M.: Analysis of stock market indices with multidimensional scaling and wavelets. Math. Probl. Eng. 2012, 1-14 (2012)

34. Lopes, A.M., Machado, J.T., Pinto, C., Galhano, A.: Multidimensional scaling visualization of earthquake phenomena. J. Seismolog. 18(1), 163-179 (2014)

35. Lopes, A.M., Andrade, J.P., Machado, J.T.: Multidimensional scaling analysis of virus diseases. Comput. Methods Programs Biomed. 131, 97-110 (2016)

36. Machado, J.T., Lopes, A.M.: Multidimensional scaling analysis of soccer dynamics. Appl. Math. Model. 45, 642-652 (2017)

37. Pinto, C.M., Lopes, A.M., Machado, J.T.: A review of power laws in real life phenomena. Commun. Nonlinear Sci. Numer. Simul. 17(9), 3558-3578 (2012)

38. Lopes, A.M., Machado, J.T., Mata, M.E.: Analysis of global terrorism dynamics by means of entropy and state space portrait. Nonlinear Dyn. 85(3), 1547-1560 (2016)

39. Tenreiro Machado, J. A., Lopes, A. M.: Computational complexity, Entropy, vol. 19, no. 2, 2017. [Online]. Available: https://www.mdpi.com/1099-4300/19/2/61

40. Machado, J.T., Lopes, A.M.: Rare and extreme events: the case of covid-19 pandemic. Nonlinear Dyn. 100, 2953-2972 (2020)

41. Machado, J.T., Rocha-Neves, J.M., Andrade, J.P.: Computational analysis of the sars-cov-2 and other viruses based on the kolmogorov's complexity and shannon's information theories. Nonlinear Dyn. 101(3), 1731-1750 (2020)
42. Machado, J.A.T.: Analysis and design of fractional-order digital control systems. Syst. Anal. Model. Simul., Gordon Breach Sci. Publ. 27(2-3), 107-122 (1997)

43. Sabatier, J., Agrawal, O. P., Machado, J. T.: Advances in fractional calculus. Springer, vol. 4, no. 9 (2007)

44. Tenreiro Machado, F. M. J.: Virginia Kiryakova, Recent history of fractional calculus. Communications in Nonlinear Science and Numerical Simulations, Elsevier, vol. 16, no. 16, pp. 1140-1153, (2011)

45. Machado, Ed., J.: Handbook of fractional calculus with applications. De Gruyter, (2019)

46. Machado, J.T.: The bouncing ball and the grünwald-letnikov definition of fractional derivative. Fract. Calculus Appl. Anal. 24(4), 1003-1014 (2021)

47. Diethelm, K., Kiryakova, V., Luchko, Y., Tenreiro Machado, J., Tarasov, V.: Trends, directions for further research, and some open problems of fractional calculus, 08 (2021)

48. Ionescu, C., Lopes, A., Copot, D., Machado, J., Bates, J.: The role of fractional calculus in modeling biological phenomena: A review. Commun. Nonlinear Sci. Numer. Simul. 51, 141-159 (2017)

49. Machado, J.T., Ma, J.: Preface: Nonlinear dynamics of covid-19 pandemic: Modeling, control, and future perspectives. Nonlinear Dyn. 101, 1525-1526 (2020)

50. Lacarbonara, W., Machado, J.T., Ma, J., Nataraj, C.: Preface: Complex dynamics of covid-19: modeling, prediction and control. Nonlinear Dyn. 106, 1129-1131 (2021)

51. Quaranta, G., Giovanni, F., Machado, J.T., Lacarbonara, W., Masri, S.F.: Understanding covid-19 nonlinear multi-scale dynamic spreading in Italy. Nonlinear Dyn. 101, 1583-1619 (2020)

Publisher's Note Springer Nature remains neutral with regard to jurisdictional claims in published maps and institutional affiliations. 